\title{
INFLUÊNCIA DA DISPOSIÇÃO, NÚMERO E TAMANHO DAS SEMENTES NO TESTE DE COMPRIMENTO DE PLÂNTULAS DE SOJA ${ }^{1}$
}

\author{
WELISON ANDRADE PEREIRA2; FILIPE LUIS SÁVIO; ALUÍZIO BORÉM"; \\ DENISE CUNHA FERNANDES DOS SANTOS DIAS ${ }^{4}$.
}

\begin{abstract}
RESUMO - O teste de comprimento de plântulas possui vantagens significativas para a avaliação do vigor de sementes. Além do baixo custo, não há necessidade de equipamentos sofisticados, nem recursos humanos altamente especializados e os resultados são obtidos rapidamente. Contudo, temse notado a presença de plântulas com hipocótilos grossos e curtos na realização deste teste quando conduzido com 20 sementes de soja, o que pode interferir nos resultados. O objetivo deste trabalho foi avaliar os efeitos do tamanho da amostra (20 e 10 sementes), diâmetro do rolo de germinação (três diâmetros) e tamanho das sementes (peneiras 12, 13 e 14) sobre os resultados do teste de comprimento de plântulas de soja. Neste teste, realizado com 20 sementes, a disposição das sementes em duas fileiras, o diâmetro do rolo de germinação e o tamanho das sementes interferiram nos resultados do teste. No teste conduzido com 10 sementes tais efeitos não foram observados, indicando que tal metodologia favorece a reprodutibilidade dos resultados.
\end{abstract}

Termos para indexação: metodologia; comprimento de plântulas; soja

\section{INFLUENCE OF THE SEED ARRANGEMENT, NUMBER AND SIZE OF SOYBEAN SEED ON SEELING LENGTH TEST}

\begin{abstract}
The seedling length testing is a good methodology for seed vigor evaluation. It's low cost, no need of sophisticated equipments, neither human resource very specialized associated with quick results has made it very popular. However, it has been observed presence of seedlings with short and tickly hypcotil, when conduced with 20 soybean seeds, which it may interfere in the results. The objective of this work was to evaluate the effect of sample size (10 and 20 seeds), germination roll diameters (three diameters) and seeds size (sieves 12, 13 and 14) on the results of the soybean seedling length. In this study, tests with 20 seeds per germination roll, with seeds arrangement in two rows, the diameter of the germination roll and the seeds size interfered in the results. However, the test with 10 seeds per germination roll did not affect the results, indicating that this favors the result reproducibility.
\end{abstract}

Index terms: methodology; seedling length; soybean

${ }^{1}$ Submetido em 25/09/2008. Aceito para publicação em 19/01/2009.

${ }^{2}$ Estudante de Pós-Graduação, Depto. de Fitotecnia, Universidade Federal de Viçosa, 36570-000 - Viçosa - MG. E-mail: welison.pereira@ufv.br

${ }^{3}$ Estudante de Iniciação Científica, Universidade Federal de Viçosa,
36570-000 - Viçosa - MG. E-mail: filipebiotech@gmail.com

${ }^{4}$ Prof. Associado Depto. de Fitotecnia, Universidade Federal de Viçosa, 36570-000 - Viçosa - MG. E-mail: borem@ufv.br; dcdias@ufv.br 


\section{INTRODUÇÃO}

A ISTA - International Seed Testing Association (Hampton e Tekrony, 1995), a AOSA - Association of Official Seed Analysis e Nakagawa (1999) sugerem a análise do crescimento das plântulas como um dos meios para avaliar o vigor de sementes. O teste de comprimento de plântulas tem como base o princípio de que lotes de sementes que originam plântulas com maior comprimento são mais vigorosos (Nakagawa, 1999). Vanzolini et al. (2007) e Hampton e Tekrony (1995) verificaram que o teste ganha em sensibilidade na detecção de diferenças sutis na qualidade fisiológica de lotes de sementes de soja quando, para a obtenção do comprimento médio da parcela, é considerado o número de sementes colocadas para germinar e não somente o número de plântulas mensuradas.

Dentre as vantagens da aplicação do teste de comprimento de plântulas está o baixo custo, pois não há necessidade de equipamentos sofisticados e nem recurso humano altamente especializado, os resultados são obtidos rapidamente e existe conexão entre este teste e a análise da massa fresca e seca de plântulas (Nakagawa, 1999). Os testes com base em medidas de comprimento e peso não correm o risco de serem afetados pela subjetividade do analista, pois os dados são obtidos de medições de dimensão e massa, fato que favorece a reprodutibilidade dos resultados (Vanzolini et al., 2007).

Contudo, por observações feitas no Laboratório de Sementes da UFV durante as avaliações do teste de comprimento deplântulas de soja, constata-se freqüentemente, a presença de plântulas normais, dotadas de hipocótilos delgados e longos, e de plântulas com os hipocótilos grossos e curtos. Como na literatura não foram encontrados relatos sobre tais aspectos, algumas hipóteses foram estudadas com o objetivo de explicar a ocorrência dessas plântulas como se a disposição das sementes em duas fileiras estaria originando uma barreira física para o desenvolvimento das plântulas ou que a disposição das sementes em duas fileiras poderia prejudicar o crescimento em comprimento das plântulas, devido ao reduzido diâmetro do rolo de papel.

O tamanho das sementes também poderia afetar o desenvolvimento em comprimento das plântulas, pois sementes maiores, na fileira superior, poderiam formar uma barreira física mais fechada ao crescimento das plântulas da fileira inferior, do que sementes de menor tamanho, já que o tamanho médio das sementes aumenta após a hidratação (Beckert et al., 2000). Foloni et al. (2006) observaram acréscimo em diâmetro nas raízes de soja desenvolvidas sob solo compactado. É possível que um processo similar possa ocorrer com os hipocótilos das plântulas da fileira inferior de sementes, em detrimento da resistência física ao seu crescimento, gerado pela fileira superior de plântulas de soja.

Costa et al. (1999) afirmaram que o peso dos cotilédones das sementes de soja de tamanho maior seria responsável pelo incremento em diâmetro do hipocótilo, como uma resposta morfológica para a sustentação de um peso maior. Assim, seria plausível admitir que uma resposta morfológica à falta de espaço para o crescimento das plântulas também pudesse estar ocorrendo no teste de comprimento de plântulas, identificado na presença de plântulas com hipocótilos reduzidos e com maior expansão radial.

Diante do exposto, o objetivo deste trabalho foi avaliar os efeitos do número de sementes da amostra, diâmetro do rolo de germinação e tamanho das sementes sobre os resultados do teste de comprimento de plântulas de soja.

\section{MATERIAL E MÉTODOS}

Os trabalhos foram realizados no Laboratório de Genética da Soja localizado no Departamento de Fitotecnia da Universidade Federal de Viçosa, MG, no segundo trimestre do ano de 2008. Foram utilizadas sementes dos cultivares CD 219 e Emgopa 315.

Inicialmente, os lotes de sementes foram caracterizados quanto ao teor de água, peso de mil sementes e germinação (primeira contagem e contagem final). O teor de água, a partir da fórmula:

$$
\left[T A=\frac{(W 1-W 2)}{W 1}\right] \text {, foi obtido pelo }
$$

método de estufa, no qual 4 repetições de 50 sementes foram pesadas (W1), colocadas para secar em estufa a $104 \pm 3^{\circ} \mathrm{C}$ $24 \mathrm{~h}^{-1} \mathrm{e}$, em seguida, pesadas novamente (W2), sendo os resultados expressos em porcentagem (Soltani et al., 2006). $O$ peso de mil sementes, em gramas, foi obtido a partir da pesagem de 8 repetições de 100 sementes, seguindo os procedimentos recomendados pelas Regras para Análise de Sementes (Brasil, 1992). O teste de germinação consistiu de 4 repetições de 50 sementes distribuídas entre folhas de papel germitest umedecidos na proporção 2,5 por $1(\mathrm{~mL}$ de água destilada por peso do papel seco em gramas) e mantidas em câmara de germinação sob temperatura controlada de $25 \pm 1^{\circ} \mathrm{C}$ por 8 dias. Os resultados foram expressos em porcentagem de plântulas normais, segundo as RAS (Brasil, 1992). A primeira contagem da germinação foi efetuada juntamente com o teste de germinação, computando-se a porcentagem de plântulas normais obtidas no quinto dia após 
a semeadura (Brasil, 1992).

Para a avaliação das hipóteses lançadas a respeito da ocorrência das plântulas com hipocótilos grossos e curtos no teste de comprimento de plântulas, foram conduzidos 2 ensaios, seguindo-se a metodologia descrita por Nakagawa (1999). No primeiro, o desenvolvimento das plântulas foi investigado em função de dois tamanhos de amostras no teste (10 e 20 sementes) e três diâmetros dos rolos de germinação ( menor, médio e maior). A amostra de 20 sementes foi disposta no terço superior do papel germitest em duas fileiras de 10 sementes cada, espaçadas $1,5 \mathrm{~cm}$, e a amostra de 10 sementes, em fileira única (Figuras 1 e 2). Quanto aos diâmetros dos rolos de germinação $\left(\varnothing_{m}=\right.$ diâmetro médio do tratamento), estes foram propositalmente obtidos durante sua confecção: um tratamento essencialmente apertado de diâmetro menor $\left(\varnothing_{m}=2,75 \mathrm{~cm}\right)$; um tratamento de diâmetro médio $\left(\varnothing_{m}=3,25 \mathrm{~cm}\right)$ e, por fim, um tratamento com o diâmetro maior $\left(\varnothing_{m}=3,7 \mathrm{~cm}\right)$. As medições deram-se ao final da confecção dos rolos de germinação, quando cada um dos quatro rolos (repetições) de cada tratamento teve o seu diâmetro medido. Em seqüência, os rolos foram mantidos em câmara de germinação sob temperatura controlada (25 \pm $1^{\circ} \mathrm{C}$ ) por sete dias.

Folhas de Papel Toalha

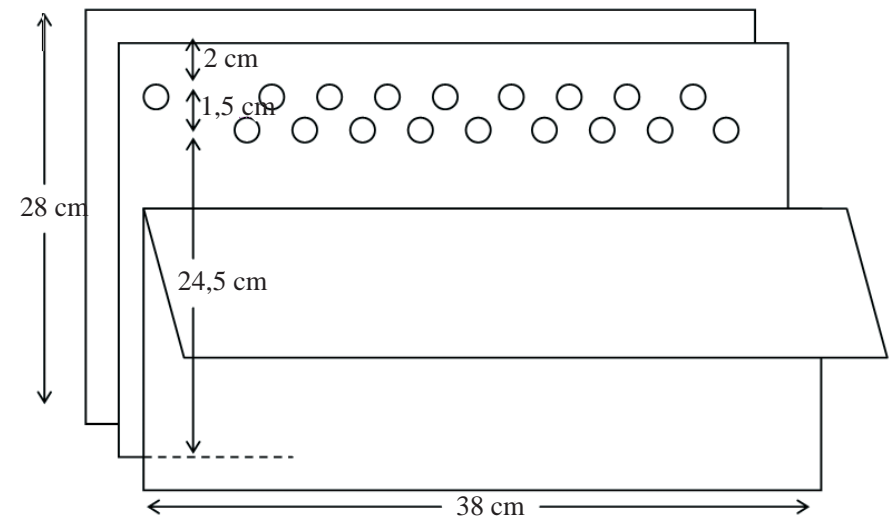

FIGURA 1. Orientação e espaçamento das sementes sobre o papel toalha para condução dos testes de peso de matéria seca e comprimento de plântulas (Nakagawa, 1999).

No teste realizado com 20 sementes, as plântulas oriundas das sementes da fileira superior foram separadas daquelas da fileira inferior e os comprimentos do hipocótilo, da radícula e total da plântula foram medidos em centímetros, fornecendo, referente à mesma repetição, o comprimento médio das plântulas da fileira superior, da fileira inferior e o comprimento médio de plântula da parcela. Do teste executado com 10 sementes foram obtidos os comprimentos médios de hipocótilo, de radícula e de plântula da parcela.

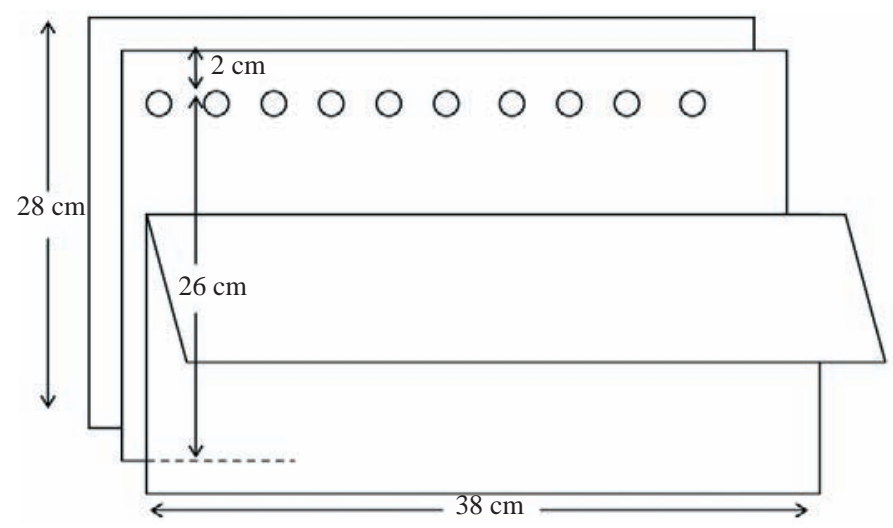

\section{FIGURA 2. Orientação e espaçamento das sementes sobre o papel toalha para condução dos testes de peso de matéria seca e comprimento de plântulas alternativamente testado.}

Sob o aspecto estatístico, neste mesmo ensaio, foram analisados dois fatoriais: no primeiro, estudou-se o fatorial $2 \mathrm{x}$ 3 (número de sementes $x$ diâmetro do rolo) com 4 repetições, no qual foram comparados o comprimento médio de plântula da amostra com 10 sementes com o comprimento médio de plântula da amostra com 20 sementes. Desse modo, os dois tamanhos de amostras (10 e 20) foram comparados entre si e em função dos três diâmetros do rolo de germinação ( menor, médio e maior). O segundo fatorial analisado foi $3 \times 3$ (fileira $\mathrm{x}$ diâmetro do rolo), com 4 repetições de 10 sementes. Por este fatorial, foram comparados os comprimentos médios de plântula da fileira superior, fileira inferior (do teste com 20 sementes) e da fileira única (do teste com 10 sementes) entre si e em função dos três diâmetros dos rolos (menor, médio, maior).

No segundo ensaio, o teste de comprimento das plântulas foi instalado com 20 sementes e nele foi estudado o fatorial 2 x 3 (fileira $x$ tamanho de sementes), com 4 repetições de 10 sementes. O primeiro dos fatores foi constituído pelas duas fileiras (superior e inferior) e o segundo fator, por sementes de três tamanhos diferentes, classificadas nas peneiras metálicas de crivos oblongos 12 (12/64 x 3/4"), 13 (13/64 x 3/4") e 14 $(14 / 64 \times 3 / 4$ "). Os rolos de germinação foram confeccionados no diâmetro médio $\left(\varnothing_{m}\right)$ de $3,25 \mathrm{~cm}$ e então mantidos em câmara de germinação sob temperatura controlada $\left(25 \pm 1^{\circ} \mathrm{C}\right)$ 
por sete dias (Brasil, 1992). Depois deste período, os rolos foram retirados da câmara de germinação e desenrolados cuidadosamente. As plântulas oriundas das sementes da fileira superior foram separadas daquelas da fileira inferior e foi mensurado o comprimento do hipocótilo, da radícula e total da plântula, em centímetros.

Nos dois ensaios, o papel germitest foi umedecido conforme descrito para o teste de germinação nas RAS (Brasil, 1992). As sementes foram distribuídas sobre as folhas de papel germitest com a micrópila voltada para a base do papel, favorecendo o crescimento em comprimento das plântulas (Krzyzanowski, 1991; Nakagawa, 1999). Após a obtenção dos comprimentos das plântulas e de suas partes (hipocótilo e radícula), os cotilédones foram removidos e os hipocótilos separados das radículas. Os hipocótilos e as radículas foram então colocados em sacos de papel distintos, os quais foram mantidos em estufa, sob temperatura de $80 \pm$ $3^{\circ} \mathrm{C}^{2} 4 \mathrm{~h}^{-1}$. Ao final deste período, foi obtido, em miligramas, o peso de massa seca do hipocótilo e radícula. Os resultados foram expressos em pesos médios, ou seja, o peso de massa seca dividido pelo número de plântulas colocadas no saco de papel para secar. O peso de massa seca por plântula foi obtido a partir da soma dos pesos médios de massa seca do hipocótilo e radícula.

Adicionalmente, foi avaliado o peso de biomassa seca por centímetro de plântula, ou seja, a densidade de biomassa (DB). Para a obtenção dos valores desta variável, expressa em miligramas por centímetro de plântula $\left(\mathrm{mg} \mathrm{cm}^{-1}\right)$, foi utilizada a fórmula $D B=\frac{\text { Peso }}{\text { Comprimento }}$. Este valor foi obtido a partir das medidas de peso e comprimento de cada plântula da parcela.

O delineamento experimental adotado foi o inteiramente casualizado em esquema fatorial simples com quatro repetições. Cada um dos três fatoriais (dois fatoriais no primeiro ensaio e um fatorial no segundo ensaio) foi analisado separadamente e foram realizados a análise de variância e o teste de médias de Tukey ao nível de 5\% de probabilidade.

\section{RESULTADOS E DISCUSSÃO}

Na Tabela 1 estão apresentadas as medidas dos diâmetros de cada rolo de germinação confeccionado. Estes diâmetros (menor, médio e maior) foram obtidos propositalmente, constituindo uma das fontes de variação avaliadas. Nos rolos de germinação de diâmetro menor, o espaço para as plântulas emergirem foi reduzido em comparação com os rolos de diâmetros médios e maiores. Esperava-se que estes últimos, de diâmetro maior, propiciassem condição mais adequada para o crescimento das plântulas e, realmente, verificou-se que os comprimentos médios das plântulas foram maiores que os observados para os rolos de menor diâmetro. Costa et al. (1999) relataram que as plântulas têm os seus hipocótilos aumentados em diâmetro quando existe alguma pressão contrária ao seu crescimento em comprimento, como sob solos compactados. Por outro lado, foi observado neste trabalho que, caso não haja resistência, a plântula cresce normalmente em comprimento, conforme as suas propriedades genéticas e fisiológicas.

TABELA 1. Diâmetros $(\varnothing)^{1 /}$ dos rolos de germinação[ $\varnothing_{1(<)}$ menor, $\varnothing_{2(\bar{x})}$ médio, $\varnothing_{3(>)}$ maior], diâmetro médio $\left(\varnothing_{m}\right)$ e variância $\left(\sigma^{2}\right)$ de cada parcela experimental, constituída por genótipo, diâmetro e repetição

\begin{tabular}{cccccccc}
\hline Genótipos & Diâmetros & $\mathrm{R} 1$ & $\mathrm{R} 2$ & $\mathrm{R} 3$ & $\mathrm{R} 4$ & $\varnothing_{m}$ & $\sigma^{2}$ \\
\hline \multirow{3}{*}{ CD219 } & $\varnothing_{1(<)}$ & 2,6 & 2,8 & 2,9 & 2,6 & 2,725 & 0,0225 \\
& $\varnothing_{2(\bar{x})}$ & 3,1 & 3,3 & 3,4 & 3,3 & 3,275 & 0,0153 \\
& $\varnothing_{3(>)}$ & 3,6 & 3,9 & 3,5 & 3,8 & 3,7 & 0,0333 \\
\hline \multirow{2}{*}{ Emgopa 315 } & $\varnothing_{1(<)}$ & 2,7 & 2,8 & 2,8 & 2,8 & 2,775 & 0,050 \\
& $\varnothing_{2(\bar{x})}$ & 3,2 & 3,3 & 3,3 & 3,1 & 3,225 & 0,095 \\
& $\varnothing_{3(>x)}$ & 3,7 & 3,8 & 3,7 & 3,6 & 3,7 & 0,081 \\
\hline
\end{tabular}

${ }^{1 /}$ Diâmetro medido em centímetros

Os valores obtidos para teor de água das sementes, primeira contagem e contagem final da germinação não diferiram entre os cultivares CD 219 e Emgopa 315. O peso de mil sementes do Emgopa 315 foi superior ao CD 219 
(Tabela 2). Não constituiu objetivo deste trabalho ,comparar os genótipos entre si, no entanto, esses dados têm a função de caracterizar os lotes de sementes estudados, demonstrando boa qualidade do material de pesquisa.

TABELA 2. Caracterização dos genótipos CD219 e Emgopa 315 para teor de água (TA), primeira contagem (PC), contagem final de germinação $(G)$ e peso de 1000 sementes (PMS).

\begin{tabular}{lllll}
\hline Genótipo & TA (\%) & PC (\%) & G (\%) & PMS (g) \\
\hline CD 219 & 10,1537 a & $93,5 \mathrm{a}$ & $96,5 \mathrm{a}$ & $141,308 \mathrm{~b}$ \\
Emgopa & $10,3738 \mathrm{a}$ & $96,5 \mathrm{a}$ & $96,5 \mathrm{a}$ & $148,172 \mathrm{a}$ \\
\hline Média & 10,2637 & 95 & 96,5 & 144,740 \\
\hline CV & 1.1705 & 1.5814 & 1.4394 & 0.6676 \\
\hline
\end{tabular}

${ }^{11}$ As médias seguidas de mesma letra na coluna não diferiram entre si pelo teste de Tukey em/no nível de $5 \%$ de probabilidade.

No teste conduzido com 20 sementes (Tabela 3), os menores comprimentos de hipocótilo $(8,53 \mathrm{~cm}-\mathrm{CD} 219$ e
11,0 cm - Emgopa 315) e de plântula (29,6 cm - CD 219 e $31,6 \mathrm{~cm}$ - Emgopa 315) foram observados no tratamento de diâmetro menor do rolo de germinação. Apesar do diâmetro médio do rolo de germinação ter reduzido o comprimento de hipocótilo e de plântula do cultivar Emgopa 315, mas não do cultivar CD 219, os resultados mostraram que o menor diâmetro do rolo de germinação, combinado ao número maior de sementes no teste (20), reduz o comprimento médio de hipocótilo e de plântula.

No teste executado com 10 sementes (Tabela 3), os comprimentos de hipocótilo e de plântula foram maiores do que os obtidos no teste conduzido com 20 sementes, principalmente nos diâmetros menor e médio do rolo de germinação. Apenas para o diâmetro maior do rolo, ambos os tratamentos (seja com 10 ou com 20 sementes) resultaram em plântulas com comprimentos estatisticamente similares (Tabela 3). Adotando a consideração de Costa et al. (1999) sobre o aumento em diâmetro do hipocótilo, pode-se, nos tratamentos conduzidos com 20 sementes, caracterizar a fileira superior de plântulas como barreira ao crescimento das plântulas da fileira inferior, pois as mesmas tiveram os seus hipocótilos reduzidos e com maior diâmetro radial, ou seja, hipocótilos curtos e grossos.

TABELA 3. Comparação das médias ${ }^{1}$ das características comprimento de hipocótilo, radícula e plântula (cm), massa seca de hipocótilo, radícula e de plântula (g), DMSH - densidade de massa seca de hipocótilo, DMSR densidade de massa seca de radícula e DMSP - densidade de massa seca de plântula $\left(\mathrm{mg} \mathrm{cm}^{-1}\right)$, para os genótipos CD 219 e Emgopa 315, em função do diâmetro do rolo de germinação (menor, médio e maior) e do tamanho da amostra de sementes do teste (20 ou 10 sementes).

\begin{tabular}{|c|c|c|c|c|c|c|c|c|c|c|}
\hline \multirow{3}{*}{ Genótipo } & \multirow[b]{3}{*}{ Amostra } & \multicolumn{9}{|c|}{ Diâmetro do rolo de germinação } \\
\hline & & Menor & Médio & Maior & Menor & Médio & Maior & Menor & Médio & Maior \\
\hline & & \multicolumn{3}{|c|}{ Comprimento do hipocótilo } & \multicolumn{3}{|c|}{ Comprimento da radícula } & \multicolumn{3}{|c|}{ Comprimento da plântula } \\
\hline \multirow{2}{*}{ CD219 } & 20 & $8.53 \mathrm{bB}$ & $10.6 \mathrm{bA}$ & $10.9 \mathrm{bA}$ & $21.0 \mathrm{aA}$ & $21.9 \mathrm{aA}$ & $21.9 \mathrm{aA}$ & $29.6 \mathrm{bB}$ & $32.6 \mathrm{bA}$ & $32.8 \mathrm{aA}$ \\
\hline & 10 & $11.5 \mathrm{aA}$ & $12.4 \mathrm{aA}$ & $12.8 \mathrm{aA}$ & $21.9 \mathrm{aA}$ & $21.9 \mathrm{aA}$ & $21.3 \mathrm{aA}$ & $33.4 \mathrm{aA}$ & $34.3 \mathrm{aA}$ & $34.1 \mathrm{aA}$ \\
\hline \multirow{3}{*}{$\begin{array}{c}\text { Emgopa } \\
315\end{array}$} & 20 & $11.0 \mathrm{bB}$ & $11.6 \mathrm{bB}$ & $13.0 \mathrm{aA}$ & $20.6 \mathrm{bA}$ & $20.6 \mathrm{bA}$ & $20.8 \mathrm{aA}$ & $31.6 \mathrm{bB}$ & $32.2 \mathrm{bB}$ & $33.8 \mathrm{aA}$ \\
\hline & 10 & $13.1 \mathrm{aA}$ & $12.9 \mathrm{aA}$ & $13.6 \mathrm{aA}$ & $21.6 \mathrm{aA}$ & $21.4 \mathrm{aA}$ & $21.3 \mathrm{aA}$ & $34.7 \mathrm{aA}$ & $34.3 \mathrm{aA}$ & $34.9 \mathrm{aA}$ \\
\hline & & \multicolumn{3}{|c|}{ Massa Seca Hipocótilo (g) } & \multicolumn{3}{|c|}{ Massa Seca Radícula (g) } & \multicolumn{3}{|c|}{ Massa Seca Plântula (g) } \\
\hline \multirow{2}{*}{ CD219 } & 20 & $35.8 \mathrm{aA}$ & $33.0 \mathrm{aB}$ & $31.8 \mathrm{bB}$ & $19.5 \mathrm{aA}$ & $20.2 \mathrm{aA}$ & $19.9 \mathrm{aA}$ & $55.3 \mathrm{aA}$ & $53.2 \mathrm{aAB}$ & $51.6 \mathrm{aB}$ \\
\hline & 10 & $33.8 \mathrm{bA}$ & $34.5 \mathrm{aA}$ & $34.1 \mathrm{aA}$ & $20.8 \mathrm{aA}$ & $19.3 \mathrm{aAB}$ & $19.1 \mathrm{aB}$ & $54.6 \mathrm{aA}$ & $53.8 \mathrm{aA}$ & $53.1 \mathrm{aA}$ \\
\hline \multirow{3}{*}{$\begin{array}{c}\text { Emgopa } \\
315\end{array}$} & 20 & $38.1 \mathrm{aA}$ & $34.8 \mathrm{aB}$ & $32.9 \mathrm{aB}$ & $19.9 \mathrm{aA}$ & $19.4 \mathrm{aA}$ & $17.9 \mathrm{aA}$ & $58.0 \mathrm{aA}$ & $54.1 \mathrm{aAB}$ & $50.9 \mathrm{aB}$ \\
\hline & 10 & $34.4 \mathrm{bA}$ & $33.4 \mathrm{aAB}$ & $31.3 \mathrm{aB}$ & $21.5 \mathrm{aA}$ & $20.3 \mathrm{aA}$ & $19.4 \mathrm{aA}$ & $55.9 \mathrm{aA}$ & $53.7 \mathrm{aAB}$ & $50.7 \mathrm{aB}$ \\
\hline & & & DMSH & & & DMSR & & & DMSP & \\
\hline \multirow{2}{*}{ CD219 } & 20 & $4.27 \mathrm{aA}$ & $3.11 \mathrm{aB}$ & $2.92 \mathrm{aB}$ & $0.92 \mathrm{aA}$ & $0.92 \mathrm{aA}$ & $0.91 \mathrm{aA}$ & $1.87 \mathrm{aA}$ & $1.63 \mathrm{aB}$ & $1.57 \mathrm{aB}$ \\
\hline & 10 & $2.93 \mathrm{bA}$ & $2.79 \mathrm{aA}$ & $2.66 \mathrm{aA}$ & $0.95 \mathrm{aA}$ & $0.88 \mathrm{aA}$ & $0.89 \mathrm{aA}$ & $1.63 \mathrm{bA}$ & $1.57 \mathrm{aA}$ & $1.56 \mathrm{aA}$ \\
\hline \multirow{2}{*}{$\begin{array}{c}\text { Emgopa } \\
315\end{array}$} & 20 & $3.53 \mathrm{aA}$ & $3.03 \mathrm{aB}$ & $2.53 \mathrm{aC}$ & $0.96 \mathrm{aA}$ & $0.94 \mathrm{aA}$ & $0.86 \mathrm{aA}$ & $1.85 \mathrm{aA}$ & $1.68 \mathrm{aB}$ & $1.50 \mathrm{aC}$ \\
\hline & 10 & $2.89 \mathrm{bA}$ & $2.69 \mathrm{aAB}$ & $2.30 \mathrm{aB}$ & $0.99 \mathrm{aA}$ & $0.96 \mathrm{aA}$ & $0.91 \mathrm{aA}$ & $1.66 \mathrm{bA}$ & $1.56 \mathrm{aAB}$ & $1.45 \mathrm{aB}$ \\
\hline
\end{tabular}

${ }^{1 /}$ Médias seguidas de mesma letra (minúsculas na vertical e maiúsculas na horizontal) não diferem estatisticamente entre si ao nível de 5\% de probabilidade pelo teste de Tukey 
Em relação à massa seca, notou-se que, apesar dos tratamentos conduzidos com 10 sementes terem resultado em plântulas com comprimento maior, estas plântulas não apresentaram os maiores pesos de massa seca, ocorrendo, inclusive, o contrário em alguns casos. Como se observa na Tabela 3, para o cultivar CD 219, sob o menor diâmetro do rolo de germinação, o tratamento executado com 20 sementes resultou num peso de massa seca de hipocótilo $(35,8 \mathrm{mg})$ superior ao encontrado no teste executado com 10 sementes (33,8 mg). Para a cultivar Emgopa 315 ocorreu o mesmo, quando, no teste com 20 sementes, o peso de massa seca de hipocótilo foi de $38,1 \mathrm{mg}$, enquanto no teste com 10 sementes foi de $34,4 \mathrm{mg}$. Em relação ao diâmetro do rolo de germinação, sempre que este fator interferiu nos resultados de biomassa, fez com que sementes germinadas sob diâmetro menor originassem plântulas com maior peso de massa seca. Estes fatos evidenciam uma resposta das plântulas sob pressão contrária ao seu crescimento. Nesta condição, mais massa seca é mobilizada para as plântulas da fileira inferior quando uma barreira física ao seu crescimento é gerada pela fileira superior de plântulas. Materechera et al. (1992) identificaram, no engrossamento das raízes, uma resposta morfológica das plantas em terrenos compactados. O engrossamento do hipocótilo pode ser uma adaptação favorável à emergência das plântulas sob pressão contrária, como foi verificado em solos com encrostamento superficial. O hipocótilo com diâmetro maior torna a plântula mais competente em emergir nesta situação adversa (Costa et al, 1999).

Por meio da característica densidade de massa seca foi verificado que as plântulas são mais densas nos rolos de germinação de diâmetro menor, o que confirma as constatações já realizadas anteriormente (Tabela 3). A partir da análise desta variável, verificou-se que o menor diâmetro do rolo de germinação e o maior número de sementes no teste influenciaram mais o desenvolvimento do hipocótilo (aumentado sua densidade) do que da radícula. Estes resultados estão de acordo com os de Foloni et al. (2006), que estudando o crescimento de plantas de soja em camadas compactadas de solo, verificaram que a resistência mecânica exercida por este não reduziu a produção de raízes. É plausível supor que a resposta das plântulas em testes de comprimento com 20 sementes (hipocótilos grossos e curtos) deva ocorrer também em terrenos compactados, pois o engrossamento do hipocótilo torna as plântulas mais eficientes para o rompimento da superfície do solo no processo de emergência. Modolo et al. (2008) observaram que o encrostamento superficial do solo retardou a emergência das plântulas de soja, o que também é coerente à ocorrência de plântulas com os hipocótilos curtos, os quais demorariam mais para ultrapassar a superfície do solo, em virtude do desenvolvimento do hipocótilo, processo anterior ao crescimento em comprimento da plântula sob estas condições, tornando-a capaz de superar a resistência física do solo.

Os resultados da Tabela 4 corroboram os da Tabela 3, além de isolar os efeitos das fileiras. Nesta tabela, encontramse comparadas as plântulas das três fileiras (superior, inferior e única), para cada genótipo separadamente, em função dos diâmetros do rolo de germinação (o menor, o médio e o maior). Quanto aos comprimentos, as plântulas originadas das sementes da fileira inferior têm seus comprimentos prejudicados, sendo este prejuízo amplificado quando em rolos com o diâmetro menor. Interpretando estes resultados de modo prático, o teste com 10 sementes em fileira única resultou em plântulas mais homogêneas quanto às suas dimensões. Plântulas maiores não apresentaram mais biomassa seca do hipocótilo, da radícula e total de plântula.

As plântulas da fileira inferior do teste conduzido com 20 sementes acumularam mais massa seca por centímetro do que as plântulas da fileira superior e do que as plântulas da fileira única do teste conduzido com 10 sementes, especialmente quando em rolos de germinação de diâmetros menor e médio. Como já discutido anteriormente, diâmetro maior do hipocótilo pode ser interpretado como adaptação à superação da resistência à emergência da plântula. Tal constatação ganhou ainda mais evidência quando, no tratamento com diâmetro maior do rolo de germinação, as plântulas das diferentes fileiras não diferiram estatisticamente quanto à densidade de massa seca do hipocótilo. Isto confirma que a fileira superior de plântulas, quando em diâmetro menor do rolo de germinação, impede o crescimento normal das plântulas da fileira inferior.

Constatado que tanto o diâmetro do rolo de germinação quanto à fileira ocupada pelas sementes influenciaram no desenvolvimento das plântulas quando o teste é executado com 20 sementes, o efeito do tamanho das sementes sobre o crescimento das plântulas também foi investigado (Tabela 5). Suspeitou-se que sementes maiores formariam uma barreira mais difícil de ser superada pelas plântulas da fileira inferior, já que embebidas, tornam-se ainda maiores em testes de germinação (Beckert et al., 2000). Considerando o hipocótilo, as plântulas da fileira superior não mostraram resposta em função do tamanho das sementes, para ambos os genótipos. Por outro lado, na fileira inferior, plântulas resultantes de sementes de tamanho maior (peneira 14) foram prejudicadas quanto ao comprimento de hipocótilo. Comparando as fileiras entre si, as plântulas oriundas das sementes dispostas na fileira inferior apresentaram comprimentos menores do que aqueles apresentados pelas 
plântulas da fileira superior, principalmente para a cultivar CD 219. Para a cultivar Emgopa 315, as sementes da peneira de crivo maior resultaram em diferenças entre fileiras quanto ao comprimento do hipocótilo. Conforme os trabalhos de Johnson \& Wax (1978) e Soltani et al. (2002), com soja e grãode-bico, respectivamente, o tamanho das sementes não tem efeito sobre as características de germinação. As constatações desses autores contribuem para a discussão dos resultados deste estudo, pois, neste foi observado efeito de tamanho de sementes. A redução no comprimento médio das plântulas da fileira inferior é explicada pelo impedimento gerado pelas plântulas da fileira superior ao crescimento das plântulas da fileira inferior. Kolak et al. (1992) observaram que o tamanho das sementes é um fator relacionado positivamente com altura de plantas, número de vagens e número de sementes, exceto com a produtividade. Lima \& Carmona (1999) por outro lado, verificaram que o tamanho das sementes não têm relação com o desempenho em campo. Controvérsias à parte, neste trabalho, o tamanho das sementes esteve inversamente relacionado ao crescimento das sementes da fileira inferior do teste.

TABELA 4. Comparação das médias ${ }^{1}$ das características comprimento do hipocótilo, radícula e plântula (cm), massa fresca e seca de hipocótilo, radícula e de plântula (g), DMSH - densidade de massa seca de hipocótilo, DMSR - densidade de massa seca de radícula e DMSP - densidade de massa seca de plântula $\left(\mathrm{mg} \mathrm{cm}^{-1}\right)$, para os genótipo CD 219 e Emgopa 315 em função do diâmetro (D) do rolo de germinação (menor diâmetro; diâmetro médio; diâmetro maior) e da fileira (F) ocupada pelas sementes (superior; inferior; fileira única).

\begin{tabular}{|c|c|c|c|c|c|c|c|c|c|c|}
\hline \multirow{3}{*}{ Genótipo } & \multirow[b]{3}{*}{ Fileira } & \multicolumn{9}{|c|}{ Diâmetro do rolo de germinação } \\
\hline & & Menor & Médio & Maior & Menor & Médio & Maior & Menor & Médio & Maior \\
\hline & & \multicolumn{3}{|c|}{ Comprimento do hipocótilo } & \multicolumn{3}{|c|}{ Comprimento da radícula } & \multicolumn{3}{|c|}{ Comprimento da plântula } \\
\hline \multirow{3}{*}{ CD219 } & Superior & $10.0 \mathrm{aB}$ & $12.2 \mathrm{aA}$ & $11.9 \mathrm{aA}$ & $22.3 \mathrm{aA}$ & $22.8 \mathrm{aA}$ & $23.1 \mathrm{aA}$ & $32.3 \mathrm{aB}$ & $35.1 \mathrm{aA}$ & $35.0 \mathrm{aA}$ \\
\hline & Inferior & $6.9 \mathrm{bB}$ & $8.9 \mathrm{bA}$ & $10.1 \mathrm{bA}$ & $19.6 \mathrm{bB}$ & $20.9 \mathrm{bA}$ & $20.8 \mathrm{bA}$ & $26.6 \mathrm{bB}$ & $29.9 \mathrm{bA}$ & $30.9 \mathrm{bA}$ \\
\hline & Única & $11.5 \mathrm{aA}$ & $12.3 \mathrm{aA}$ & $12.8 \mathrm{aA}$ & $21.9 \mathrm{aA}$ & $21.9 \mathrm{abA}$ & $21.3 \mathrm{bA}$ & $33.4 \mathrm{aA}$ & $34.3 \mathrm{aA}$ & $34.1 \mathrm{aA}$ \\
\hline \multirow{3}{*}{$\begin{array}{c}\text { Emgopa } \\
315\end{array}$} & Superior & $12.7 \mathrm{aA}$ & $13.1 \mathrm{aA}$ & $13.6 \mathrm{aA}$ & $21.9 \mathrm{aA}$ & $21.9 \mathrm{aA}$ & $21.9 \mathrm{aA}$ & $34.7 \mathrm{aA}$ & $35.0 \mathrm{aA}$ & $35.5 \mathrm{aA}$ \\
\hline & Inferior & $8.7 \mathrm{bB}$ & $10.1 \mathrm{bB}$ & $12.5 \mathrm{aA}$ & $19.3 \mathrm{bA}$ & $19.2 \mathrm{bA}$ & $19.7 \mathrm{bA}$ & $28.6 \mathrm{bB}$ & $29.3 \mathrm{bB}$ & $32.2 \mathrm{bA}$ \\
\hline & Única & $12.1 \mathrm{aA}$ & $12.4 \mathrm{aA}$ & $13.6 \mathrm{aA}$ & $21.6 \mathrm{aA}$ & $21.2 \mathrm{aA}$ & $21.3 \mathrm{aA}$ & $33.7 \mathrm{aA}$ & $33.6 \mathrm{aA}$ & $34.9 \mathrm{aA}$ \\
\hline & & \multicolumn{3}{|c|}{ Massa Seca Hipocótilo (g) } & \multicolumn{3}{|c|}{ Massa Seca Radícula (g) } & \multicolumn{3}{|c|}{ Massa Seca Plântula (g) } \\
\hline \multirow{3}{*}{ CD219 } & Superior & $36.4 \mathrm{aA}$ & $34.4 \mathrm{aA}$ & $31.3 \mathrm{bB}$ & $18.6 \mathrm{bA}$ & $19.0 \mathrm{bA}$ & $18.5 \mathrm{bA}$ & $55.0 \mathrm{aA}$ & $53.4 \mathrm{aA}$ & $49.8 \mathrm{bB}$ \\
\hline & Inferior & $35.3 \mathrm{abA}$ & $31.6 \mathrm{bB}$ & $32.2 \mathrm{abB}$ & $20.3 \mathrm{abA}$ & $21.4 \mathrm{aA}$ & $21.2 \mathrm{aA}$ & $55.6 \mathrm{aA}$ & $53.1 \mathrm{aA}$ & $53.4 \mathrm{aA}$ \\
\hline & Única & $33.8 \mathrm{bA}$ & $34.5 \mathrm{aA}$ & $34.1 \mathrm{aA}$ & $20.8 \mathrm{aA}$ & $19.3 \mathrm{bA}$ & $19.0 \mathrm{bA}$ & $54.6 \mathrm{aA}$ & $53.8 \mathrm{aA}$ & $53.1 \mathrm{aA}$ \\
\hline \multirow{3}{*}{$\begin{array}{c}\text { Emgopa } \\
315\end{array}$} & Superior & $37.5 \mathrm{abA}$ & $35.1 \mathrm{aAB}$ & $32.9 \mathrm{aB}$ & $18.4 \mathrm{bA}$ & $18.4 \mathrm{aA}$ & $17.8 \mathrm{aA}$ & $56.0 \mathrm{aA}$ & $53.5 \mathrm{aAB}$ & $50.7 \mathrm{aB}$ \\
\hline & Inferior & $38.7 \mathrm{aA}$ & $34.4 \mathrm{aB}$ & $33.0 \mathrm{aB}$ & $21.3 \mathrm{aA}$ & $20.3 \mathrm{aAB}$ & $18.0 \mathrm{aB}$ & $60.0 \mathrm{aA}$ & $54.7 \mathrm{aB}$ & $51.0 \mathrm{aB}$ \\
\hline & Única & $34.4 \mathrm{bA}$ & $33.4 \mathrm{aA}$ & $31.3 \mathrm{aA}$ & $21.5 \mathrm{aA}$ & $20.3 \mathrm{aA}$ & $19.4 \mathrm{aA}$ & $55.9 \mathrm{aA}$ & $53.7 \mathrm{aAB}$ & $50.7 \mathrm{aB}$ \\
\hline \multirow{4}{*}{ CD219 } & & \multicolumn{3}{|c|}{ DMSH } & \multicolumn{3}{|c|}{ DMSR } & \multicolumn{3}{|c|}{ DMSP } \\
\hline & Superior & $3.71 \mathrm{bA}$ & $2.82 \mathrm{bB}$ & $2.64 \mathrm{aB}$ & $0.83 \mathrm{bA}$ & $0.83 \mathrm{bA}$ & $0.80 \mathrm{bA}$ & $1.70 \mathrm{bA}$ & $1.52 \mathrm{bB}$ & $1.42 \mathrm{bB}$ \\
\hline & Inferior & $5.12 \mathrm{aA}$ & $3.57 \mathrm{aB}$ & $3.21 \mathrm{aB}$ & $1.04 \mathrm{aA}$ & $1.02 \mathrm{aA}$ & $1.02 \mathrm{aA}$ & $2.09 \mathrm{aA}$ & $1.77 \mathrm{aB}$ & $1.73 \mathrm{aB}$ \\
\hline & Única & $2.93 \mathrm{cA}$ & $2.79 \mathrm{bA}$ & $2.66 \mathrm{aA}$ & $0.95 \mathrm{aA}$ & $0.88 \mathrm{bA}$ & $0.89 \mathrm{bA}$ & $1.63 \mathrm{bA}$ & $1.57 \mathrm{bA}$ & $1.56 \mathrm{bA}$ \\
\hline \multirow{3}{*}{$\begin{array}{c}\text { Emgopa } \\
315\end{array}$} & Superior & $2.95 \mathrm{bA}$ & $2.70 \mathrm{bA}$ & $2.42 \mathrm{aA}$ & $0.84 \mathrm{cA}$ & $0.84 \mathrm{bA}$ & $0.81 \mathrm{aA}$ & $1.61 \mathrm{bA}$ & $1.53 \mathrm{bA}$ & $1.43 \mathrm{aA}$ \\
\hline & Inferior & $4.52 \mathrm{aA}$ & $3.48 \mathrm{aB}$ & $2.65 \mathrm{aC}$ & $1.11 \mathrm{aA}$ & $1.05 \mathrm{aA}$ & $0.91 \mathrm{aB}$ & $2.15 \mathrm{aA}$ & $1.87 \mathrm{aB}$ & $1.58 \mathrm{aC}$ \\
\hline & Única & $2.89 \mathrm{bA}$ & $2.69 \mathrm{bA}$ & $2.30 \mathrm{aA}$ & $0.99 \mathrm{bA}$ & $0.96 \mathrm{aA}$ & $0.91 \mathrm{aA}$ & $1.66 \mathrm{bA}$ & $1.60 \mathrm{bAB}$ & $1.45 \mathrm{aB}$ \\
\hline
\end{tabular}

${ }^{1 /}$ Médias seguidas de mesma letra (minúsculas na vertical e maiúsculas na horizontal) não diferem estatisticamente entre si em/no nível de 5\% de probabilidade pelo teste de Tukey 
TABELA 5. Comparação das médias ${ }^{1}$ das características comprimento de hipocótilo, radícula e plântula (cm), massa fresca e seca de hipocótilo, radícula e de plântula (g), DMSH - densidade de massa seca de hipocótilo, DMSR - densidade de massa seca de radícula e DMSP - densidade de massa seca de plântula $\left(\mathrm{mg} \mathrm{cm}^{-1}\right)$, para os genótipos CD 219 e Emgopa 315, em função da (F) fileira ocupada pelas sementes (superior; inferior) e do tamanho das sementes (P) classificadas em peneiras P12, P13 e P14.

\begin{tabular}{|c|c|c|c|c|c|c|c|c|c|c|}
\hline \multirow{3}{*}{ Genótipo } & \multirow[b]{3}{*}{ Fileira } & \multicolumn{9}{|c|}{ Peneira } \\
\hline & & 12 & 13 & 14 & 12 & 13 & 14 & 12 & 13 & 14 \\
\hline & & \multicolumn{3}{|c|}{ Comprimento do hipocótilo } & \multicolumn{3}{|c|}{ Comprimento da radícula } & \multicolumn{3}{|c|}{ Comprimento da plântula } \\
\hline \multirow{2}{*}{ CD219 } & Superior & $12.77 \mathrm{aA}$ & $13.36 \mathrm{aA}$ & $12.23 \mathrm{aA}$ & $21.6 \mathrm{aB}$ & $22.5 \mathrm{aAB}$ & $22.8 \mathrm{aA}$ & $34.4 \mathrm{aA}$ & $35.9 \mathrm{aA}$ & $35.1 \mathrm{aA}$ \\
\hline & Inferior & $10.89 \mathrm{bA}$ & $10.92 \mathrm{bA}$ & $8.93 \mathrm{bB}$ & $19.7 \mathrm{bB}$ & $19.9 \mathrm{bAB}$ & $20.9 \mathrm{bA}$ & $30.6 \mathrm{bA}$ & $30.9 \mathrm{bA}$ & $29.9 \mathrm{bA}$ \\
\hline \multirow{2}{*}{ Emgopa 315} & Superior & $13.36 \mathrm{aA}$ & $13.84 \mathrm{aA}$ & $13.08 \mathrm{aA}$ & $21.82 \mathrm{aA}$ & $21.73 \mathrm{aA}$ & $21.93 \mathrm{aA}$ & $35.18 \mathrm{aA}$ & $35.58 \mathrm{aA}$ & $35.02 \mathrm{aA}$ \\
\hline & Inferior & $12.55 \mathrm{aA}$ & $12.64 \mathrm{aA}$ & $10.11 \mathrm{bB}$ & $19.85 \mathrm{bA}$ & $19.68 \mathrm{bA}$ & $19.23 \mathrm{bA}$ & $32.40 \mathrm{bA}$ & $32.32 \mathrm{bA}$ & $29.34 \mathrm{bB}$ \\
\hline \multirow{3}{*}{ CD219 } & & \multicolumn{3}{|c|}{ Massa Seca Hipocótilo (g) } & \multicolumn{3}{|c|}{ Massa Seca Radícula (g) } & \multicolumn{3}{|c|}{ Massa Seca Plântula (g) } \\
\hline & Superior & $20.2 \mathrm{bC}$ & $26.9 \mathrm{aB}$ & $34.4 \mathrm{aA}$ & $12.6 \mathrm{bB}$ & $13.9 \mathrm{bB}$ & $19.0 \mathrm{bA}$ & $32.8 \mathrm{bC}$ & $40.9 \mathrm{aB}$ & $53.4 \mathrm{aA}$ \\
\hline & Inferior & $21.8 \mathrm{aC}$ & $26.6 \mathrm{aB}$ & $31.6 \mathrm{bA}$ & $15.5 \mathrm{aB}$ & $16.6 \mathrm{aB}$ & $21.4 \mathrm{aA}$ & $37.4 \mathrm{aC}$ & $43.3 \mathrm{aB}$ & $53.1 \mathrm{aA}$ \\
\hline \multirow{2}{*}{ Emgopa 315} & Superior & $23.6 \mathrm{aC}$ & $28.8 \mathrm{aB}$ & $35.1 \mathrm{aA}$ & $13.2 \mathrm{aB}$ & $14.3 \mathrm{bB}$ & $18.4 \mathrm{bA}$ & $36.8 \mathrm{aC}$ & $43.1 \mathrm{aB}$ & $53.5 \mathrm{aA}$ \\
\hline & Inferior & $23.8 \mathrm{aC}$ & $29.5 \mathrm{aB}$ & $34.4 \mathrm{aA}$ & $14.4 \mathrm{aB}$ & $15.9 \mathrm{aB}$ & $20.3 \mathrm{aA}$ & $38.2 \mathrm{aC}$ & $45.5 \mathrm{aB}$ & $54.7 \mathrm{aA}$ \\
\hline \multirow{3}{*}{ CD219 } & & \multicolumn{3}{|c|}{ DMSH } & \multicolumn{3}{|c|}{ DMSR } & \multicolumn{3}{|c|}{ DMSP } \\
\hline & Superior & $1.59 \mathrm{bC}$ & $2.02 \mathrm{bB}$ & $2.82 \mathrm{bA}$ & $0.58 \mathrm{bB}$ & $0.62 \mathrm{bB}$ & $0.83 \mathrm{bA}$ & $0.96 \mathrm{bC}$ & $1.14 \mathrm{bB}$ & $1.52 \mathrm{bA}$ \\
\hline & Inferior & $2.01 \mathrm{aC}$ & $2.46 \mathrm{aB}$ & $3.57 \mathrm{aA}$ & $0.79 \mathrm{aB}$ & $0.83 \mathrm{aB}$ & $1.02 \mathrm{aA}$ & $1.22 \mathrm{aC}$ & $1.40 \mathrm{aB}$ & $1.77 \mathrm{aA}$ \\
\hline \multirow{2}{*}{ Emgopa 315} & Superior & $1.77 \mathrm{aB}$ & $2.09 \mathrm{aB}$ & $2.70 \mathrm{aA}$ & $0.60 \mathrm{bB}$ & $0.66 \mathrm{bB}$ & $0.84 \mathrm{bA}$ & $1.04 \mathrm{bC}$ & $1.21 \mathrm{bB}$ & $1.53 \mathrm{bA}$ \\
\hline & Inferior & $1.90 \mathrm{aB}$ & $2.34 \mathrm{aB}$ & $3.48 \mathrm{aA}$ & $0.72 \mathrm{aB}$ & $0.81 \mathrm{aB}$ & $1.05 \mathrm{aA}$ & $1.18 \mathrm{aC}$ & $1.41 \mathrm{aB}$ & $1.87 \mathrm{aA}$ \\
\hline
\end{tabular}

${ }^{1 /}$ Médias seguidas de mesma letra (minúsculas na vertical e maiúsculas na horizontal) não diferem estatisticamente entre si em/no nível de 5\% de probabilidade pelo teste de Tukey

Em relação à massa seca, as sementes de maior tamanho mobilizaram mais massa seca para suas plântulas, para o hipocótilo e radícula. Em termos de fileira, os maiores comprimentos de plântulas não significaram maiores pesos secos de plântulas, como verificado nos testes anteriores.

Por fim, quanto às densidades, sempre que verificado efeito de fileiras sobre o crescimento das plântulas, aquelas da fileira inferior apresentaram os maiores valores, ou seja, mais peso de massa seca por centímetro do que as plântulas da fileira superior, considerando adicionalmente que sementes maiores mobilizaram mais massa seca e foram mais densas.

Com base nestas discussões e resultados, nos testes conduzidos com amostras de 20 sementes distribuídas em duas fileiras, tanto o diâmetro do rolo de germinação quanto o tamanho das sementes podem constituir fontes de variação não controladas, interferindo nos resultados obtidos para 0 comprimento médio das plântulas. Nesta condição, onde houve redução nos comprimentos médios de plântula, foi verificado engrossamento dos hipocótilos, principalmente nas plântulas da fileira inferior do teste. Portanto, considerando que o teste de comprimento de plântulas tem como princípio julgar o vigor de lotes de sementes tendo como base o desempenho das plântulas em crescimento (Nakagawa, 1999), é importante que nenhum fator não controlado influencie os resultados, o que fatalmente induziria à interpretações equivocadas a respeito dos lotes de sementes analisados.

Deste modo, considerando o tamanho da amostra utilizada no teste de comprimento das plântulas (20 ou 10 sementes), os resultados dos testes conduzidos com 10 sementes são menos afetados pelas fontes de variações não controladas estudadas neste trabalho (diâmetro do rolo de germinação e tamanho das sementes).

\section{CONCLUSÕES}

O teste de comprimento de plântulas conduzido com 10 sementes é menos sensível às fontes de variação investigadas neste estudo (diâmetro do rolo de germinação e tamanho das sementes) e possibilita maior reprodutibilidade dos resultados do que o teste conduzido com 20 sementes.

\section{REFERÊNCIAS}

\section{ASSOCIATION OF OFFICIAL SEED ANALYSTS. Seed}


vigor testing handbook. East Lansing: AOSA, 1923. 93 p.

BRASIL. Ministério da Agricultura e da Reforma Agrária.

Regras para análise de sementes. Brasília, DF: SNDA/ DNDV/CLAV, 1992. 365 p.

COSTA, J.A.; PIRES, J.L.F.; THOMAS, A.L.; ALBERTON, M. Comprimento e índice de expansão radial do hipocótilo de cultivares de soja. Ciência Rural, v. 29, p. 609-612, 1999.

FOLONI, J.S.S.; LIMA, S.L.; BÜLL, L.T. Crescimento aéreo e radicular da soja e de plantas de cobertura em camadas compactadas de solo. Revista Brasileira de Ciência do Solo, v. 30, p. 49-57, 2006.

HAMPTON, J.G. TEKRONY, D.M. Handbook of vigour test methods. 3 ed. Zürich: ISTA, 1995, 117 p.

KRZYZANOWSKI, F.C. Teste de comprimento de raiz de plântula de soja. Informativo ABRATES, v. 2, p. 11-14, 1991.

MATERECHERA, S.A.; ALSTON, A.M.; KIRBY, J.M.; DEXTER, A.R. Influence of root diameter on the penetration of seminal roots into a compacted subsoil. Plant Soil, v. 144, p. 297-303, 1992.

MODOLO, A.J.; FERNANDES, H.C.; SCHAEFER, C.E.G.; SILVEIRA, J.C.M. Efeito da compactação do solo sobre a emergência de plântulas de soja em sistema de plantio direto. Ciência e Agrotecnologia, v. 32, p. 1259-1265, 2008.

NAKAGAWA, J. Testes de vigor baseados na avaliação das plântulas. In: KRZYZANOSKI, F.C.; VIEIRA, R.D.; FRANÇA NETO, J.B. (Ed.). Vigor em sementes: conceitos e testes. Londrina: ABRATES, 1999, p.2.1-2.24. 